\title{
Factories of the future: operation and perspectives of development
}

\author{
Paul Chang ${ }^{1}$, Diana Kaledina ${ }^{2}$, Anatoly Popovich $^{3}$, and Andrey Volkov ${ }^{3 *}$ \\ ${ }^{1}$ Buffalo Machinery Co., Ltd. 428-46, 56, Lane 318, Desheng Road, Daya District, Taiwan \\ ${ }^{2}$ JSC "Baltic Industrial Company", 188660, Leningrad region, Vsevolozhsk region, building 1, office \\ 212, street of 28th km of Ring highway, Russian Federation \\ ${ }^{3}$ National Technological Initiatives Center "New Industrial Technologies" of Peter the Great St. \\ Petersburg Polytechnic University, 195251, Polytechnicheskaya st., 29, Russian Federation
}

\begin{abstract}
The role of automation in industrial development was highlighted. We discussed the significance of automation for creating the factory of the future. We presented the basic criteria of efficiency of automated factories. We analyzed the experience of creating automated factories, indicated the basic scientific-technical problems related to automation of production and suggested the ways to overcome them. We listed the basic factors of scientific-technical progress that should be the basis for automation of production and indicated its basic elements. We showed the role of technological equipment, tools and accessories. We analyzed the results of state support of industry.
\end{abstract}

Creating the "factory of the future" is primarily characterized by a high level of automation of production and has been a popular idea throughout the entire history of industrial development [1].

The idea of automation was especially popular during the last three decades of the USSR. It would be a major mistake to discard the experience accumulated in that sphere. Automation of production is primarily based of the theory of productivity of machines and labor presented in the works by professor G. A. Shaumian in 1946 [1]. The keystone of this theory is the notion of the growth rate in the productivity of social labor that was used as the basic index in all the directives of the communist party of the USSR. The expression "social labor" implied considering all the costs for manufacturing the commodity, including the cost of creating the equipment and constructing production facilities. This theoretical criterion of efficiency of automation, which was used throughout the period of the developed socialism, is unquestionable.

The notion of the "factory of the future" is close to the notions "FAP" (Flexible Automated Production), FPS (Flexible Production System), FMS (Flexible Manufacturing System) and CAM (Computer-Aided Manufacturing) introduced during the late XX century [2]. The keyword here is the term "flexibility". Creating a modern automated production system is time-consuming and costly, whereas the "period of usefulness" of many commodities is conditioned by fashion and scientific-technical progress. In most cases, a new factory has to be created before the particular image of the object of manufacturing can be

\footnotetext{
* Corresponding author: volkov-and-1@yandex.ru
} 
detailed. It is this property of flexibility makes it possible to adapt the production system to quickly-changing situations. At the same time, the rate of change in the conditions tends to increase.

The fundamental basis of the "factory of the future" is a universal digital control platform for all the stages of creating the product: from $R \& D$ to testing the ready product. Undoubtedly, it is an important direction in creating modern factories, but it is not the key factor in developing up-to-date industry. For the first time, the basic scientific provisions for automation on the basis of all-through computerization of designing and production in the USSR were formulated in the research made under supervision of S. A. Mayorov and G. V. Orlovsky and published in 1983 in the Leningrad branch of "Mashinostroyeniye" publishing house [3].

For the first time in our country, the attempts to implement this concept were made within the framework of an ambitious "Targeted complex territorial-industrial development program for Leningrad and Leningrad district on the basis of automation with the wide use of computer technologies for the period 1984-1985 and up to 1990" that was named "Intensification-90" [4]. The experience of creating FPS in the USSR within the framework of this program that was spread throughout the country without proper consideration was quite negative for most industries. Erroneous and dogmatic financial and material investment into industry thoroughly undermined the economic potential of the country. The reasons for failure were the following: firstly, the ill-considered selection of technological processes for implementation in FPS, whereas the efficiency of their automation could vary tenfold depending on their physical essence, with similar costs; secondly, the type of production was not taken into consideration (mass, serial or single-item production), which affects the degree of flexibility of the equipment, and, therefore, its cost; thirdly, the level of automation was raised without good reason, even though specialists have known for a long time that each next stage of automation is less efficient than the previous one; fourthly, creating sophisticated technical systems was done in one stage, which unreasonably extended the period required for the FPS to reach the full production capacity or, sometimes, due to low reliability of particular sub-systems, it was not achieved at all.

For example, an FPS with a high level of automation for manufacturing printed circuit boards is efficient with any type of production. Circuit boards can easily be universalized, the production is highly fail-safe and the components are highly standardized. On the other hand, creating a highly-automated FPS (in one stage only) for small-series mechanic processing of cast billets is problematic. The main particular feature of such production is a wide or weakly predictable nomenclature of products, the ratio between the cost of automation of the main and secondary processes, as well as a significant difference between the input of the of the main and secondary processes in the overall labor consumption and, therefore, in the cost of a particular product.

The analysis of the accumulated experience shows that, during creation of modern production systems, the following provisions should be considered:

Firstly, the nomenclature of production should be thoroughly examined with consideration of the possible variability of technological processes and perspectives of scientific-technical development of the particular industry.

Secondly, the introduction of the equipment into operation should be stage-wise so as to ensure the adequate increase in the level of automation. For example, for metal processing, the following sequence of commissioning can be proposed: the basic technological equipment - computer-controlled machine tools, automated storage spaces system, automated dispatching system, automated transport, automated accumulation storage systems, industrial robots. Stage-wise implementation of the project makes it possible to adjust production technologies one after another as well as significantly cut down the singleinvestment amount while preserving high economic efficiency (productivity of the social 
labor). For this example, the main problem is selection of the nomenclature and the amount of the processing equipment units. The basis for approaching the above problem was given in the works by professor A. P. Sokolovsky on classifying the machine parts and typification of the corresponding technological processes for mass production during 1939-1955 [5]. The final stage of this process - automation of transportation and cargo handling - can be quite costly, but with little decrease in the production cost (the growth of productivity of the social labor).

Analyzing the state of domestic machine engineering, we cannot ignore the key issue of the modern tools and technological accessories. For example, the industrial magazine "Stankoinstrument" published an editor's comment stating the advent of the long-awaited industrial revolution in metal processing" symbolized by development of the platform CoroPlus manufactured by Sandvik Coromand, the world leader in metal processing. The authors of the concept think that it will ensure unprecedented progress. The system CoroPlus implies integration of all the tools sensors, algorithms, analytical capabilities and cloud technologies in one system and it does not pay a lot of attention to tools proper, its design and material. One of the leading specialists in the theory of cutting, professor of Michigan university V. P. Astakhov states that the reserve for increasing the durability of tools and the productivity of processing is determined by its design. In his works, he indicated the significant errors in the theory of processing by cutting that have been confirmed by experiments and are still relevant $[3,6]$.

The significance of creating high-quality tools and accessories to increase the productivity of labor and efficiency of machine-tools were brilliantly reflected in the report of the people's commissary of heavy machinery engineering V. A. Malyshev in the XIX congress of $\mathrm{VKPb}$ in 1939 [7]. However, the issue with Russian-made tools and accessories still remains unsolved. So it seems that a very important problem of diagnosing the state of the cutting surfaces has suddenly become prevalent over the tool itself, its design and material.

Another issue regards the problems of automated designing of technological processes. In most cases, they are not related to the problems of automation of the production processes and can be easily implemented in a stage-wise manner, with consideration of nomenclature and type of production. It is easy to purchase a complete software set for the designtechnological department, but ensuring its efficient use is often very problematic because of the functional redundancy or a stage-wise manner of implementation.

Creating the "smart factories", as they are called, is very interesting and perspective in the scientific aspect, but their economic efficiency in the RF at the present moment is doubtful. The industry requires factories with a balanced set of technological equipment and accessories to manufacture competitive product for the Russian market that should greatly exceed the share of the export. The basis for the industry of the present and the future is still using the metal processing machine-tools and technological accessories. During the latest years, the Ministry of Industry and Trade has been attempting to change the tide and ensure a steady growth in productivity of modern machine-tools and equipment. The schemes of state support have not been sufficiently elaborated for this task to be solved.

At the present time, "smart factories" are a scientific "hi-tech" rather than the actual necessity for the Russian economy. Development of this concept is undoubtedly important, but it should not substitute the actual market demands for industrial development. So, the attention to the overall "computerization and cloud technologies in production" can be given after the factory itself has been created. It is no good to provide unconditional state financial support of such "high-tech" directions in the amounts exceeding the support of the actual, not virtual equipment, tools and accessories, so as to avoid the mistakes made by the program "Intensification-90" that were spread throughout the country and contributed to the collapse of the soviet economy. 
Separate attention should be paid to the foreign experience and equipment. Industrial development requires significant modernization of the existing technologies, as well as creating new ones. Additive technologies play a significant role here.

Additive technologies (AT), or technologies of layer-wise synthesis, are currently one of the perspective production processes that have been actively developing. They provide engineers with an innovative approach to designing and manufacturing, as compared to the traditional methods of casting and metal-cutting.

In many cases, using additive technologies provides more flexibility in selecting the configuration of the article, which makes it possible to optimize the weight and functionality of the article due to using complex 3D shapes, designing thinner walls, as well as combining several functional parts so as to manufacture them as a single article [8]. It is noteworthy that the time required to manufacture the pilot articles is much shorter (the R\&D stage is shorter), and the material consumption is smaller.

Additive technologies is a generic name for the technologies of manufacture by the data of the digital model (a CAD model) by the method of layer-wise adding of the material (whence the name, "additive").

The article is created in the layer-wise manner by forming one after another layer of some or other material that is hardened or fixed in accordance with the configuration of the CAD model and joining each subsequent layer to the previous one $[9,10]$.

The companies manufacturing the equipment for using additive methods have given various names to these technologies [9]. Due to this, there is some uncertainty in the literature as to the names of various technologies. In order to solve this question, the American organization ASTM International (American Society for Testing and Materials) dealing in development of technical standards for a wide range of materials, articles, systems and services, recommended two basic terms - Additive Fabrication (AF) and Additive Manufacturing (AM), as well as their "legitimate" synonyms, such as "additive processes", "additive techniques", "additive layer manufacturing", "layer manufacturing" and "freeform fabrication". They all have the Russian equivalents "additive technologies", "additive manufacturing", as well as the "technologies of layer-wise synthesis".

AT can be classified according to the following characteristics: the model materials selected (liquid, granular, sheets, threads); the method of forming the layer; the method of hardening or fixing the layer etc.

Attention to additive technologies, "direct build-up" of metal articles, as an alternative to the traditional technological methods of manufacture, was first drawn in the aircraft, spacecraft and power-generating engineering industry. The motive was economic plausibility. Additive technologies are often less costly than the traditional technologies, and they often provide new capabilities for manufacturing. For example, it can allow manufacturing parts and die mold having complex 3D shapes, with cooling channels of arbitrary configuration, which cannot be done with the traditional methods of mechanical processing [11].

Additive technologies have some limitations and drawbacks of their own [12]:

- currently, they can only be used with a limited range of materials;

- in some cases, supporting structures are required, and they need to be removed from the finished item afterwards;

- the size of the manufactured article is limited to the size of the working chamber of the particular manufacturing installation.

At the present time, the convenience of additive technologies is a confirmed fact. Besides the lower costs of manufacture, additive technologies make it possible to significantly shorten the period for obtaining the final product. Manufacturing can be started immediately upon completion of the design stage. No rigging is necessary. Therefore, the period from designing to obtaining the final product can be shortened from several weeks to several days [12]. 
Currently, large foreign companies dealing in aircraft manufacturing are actively developing and implementing additive technologies into their technological processes. In particular, the company Boeing has created a large R\&D facility for additive technologies in St.-Louis. It deals in manufacturing prototypes from polymeric materials, as well as the ready parts of gas-turbine engines. For example, this company uses additive technologies for manufacturing inlet channels for engines of high-altitude aircraft. This made it possible to manufacture and dispatch the parts to the customer in two hours after receiving the order.

The company Airbus uses the technology of selective laser melting to reduce the weight of a swivel joint by using strong but lightweight meshed structures (Fig. 1) [13].

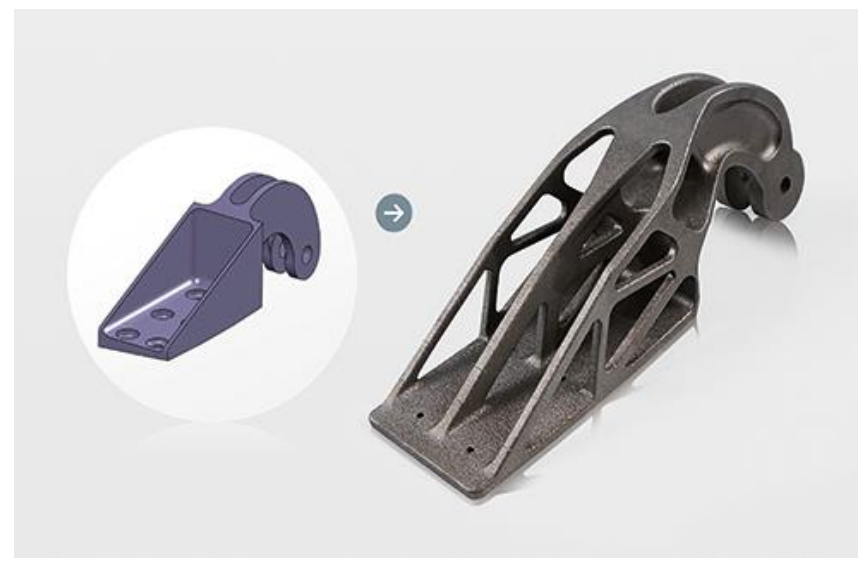

Fig. 1. A swivel joint before and after optimizing the design for additive manufacturing [13]

At the moment, GE Aviation have completely transferred the process of manufacturing nozzles of gas-turbine engines to additive technologies. The company GE uses 300 installations, and is planning to manufacture more than 100 thousand parts using additive technologies by the year 2020 [14].

The California-based company SpaceX widely used additive technologies to build their "Super Draco" engine for the next-generation spacecraft Dragon V2. In particular, the combustion chamber was manufactured using 3D printing methods [15]. The American agency (NASA) is pioneering the use of additive technologies for manufacturing parts for the space truck Space Launch System [16].

Fundamental research in the leading countries to develop methods and algorithms to use the capabilities provided by additive technologies have brought about a new class of systems - named "hybrid systems" - that use the advantages of both the additive and the subtractive technologies (machining, drilling, milling etc.) requiring no labor-consuming postprocessing.

For example, a Japanese-German company DMG-MORI (the Japanese machine-building company MORI SEIKI CO. and the German machine-tool manufacturer Gildemeister AG) created a hybrid installation LASERTEC 65 3D (Fig. 2) [17]. 


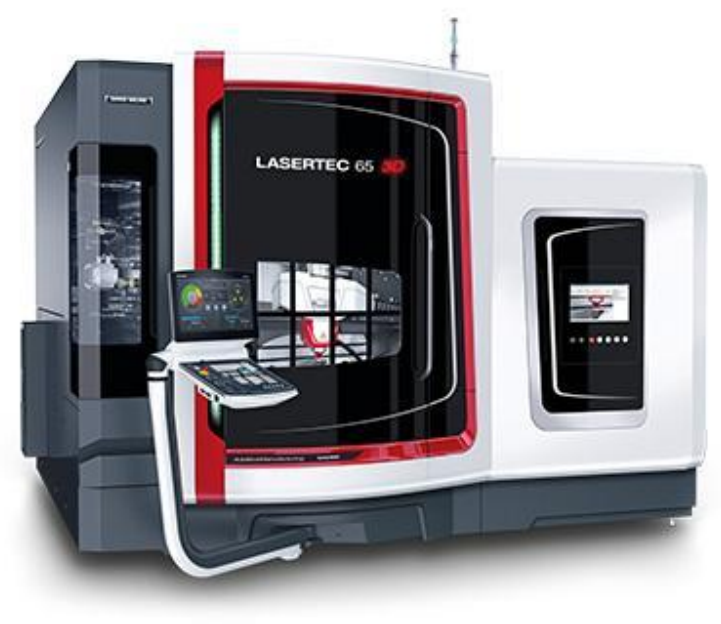

Fig. 2. A hybrid installation DMG MORI LASERTEC 65 3D [17].

At the present time, many companies worldwide are developing their own models of production equipment to use similar technological principles.

This type of installations can fully utilize the idea of the "factories of the future" from the technological viewpoint, and it completely complies with the concept "Industry 4.0".

\section{References}

1. G. A. Shaumyn (ed.), Autamatization of production processes (High school Publ., Moscow, 1967)

2. S. A. Maiorova, G. V. Orlovskiy (eds), Flexible autoamatic production (Mashinostroenie, Leningrad, 1983)

3. V. P. Astakhov, Izvestiya TulGU. Technical sciences. 8 (2016)

4. S.G. Lagushkin, Scientific and technical news SPBPU. St. Petersburg State Polytechnical University Journal. Humanities and Social Sciences 4 (208) (2014)

5. G. P. Sokolovskiy, Scientific fundamentals of the technology of machinery manufacturing. (State scientific-technical publishing house machinery manufacturing literature, Moscow, 1955)

6. Hill R, Journal of the Mechanics and Physics of Solids. 3 (1954)

7. Verbatim report. XVIII Congress of the Communist Party. March 10-21, 1939 (OGIZ, Moscow, 1939)

8. S. Hashmi, ComprehensiveMaterialsProcessing. (Newnes, 2014)

9. M. Zlenko, A. A. Popovich, I. N. Mutylina, Additive technologies in machinery manufacturing. (Publishing Politech. University, Saint Petersburg, 2013)

10. E. C. Santos, et al. Int. J. Mach. Tools Manuf. 46(12-13) (2006)

11. V. M. Dovbysh, P. V. Zabednov, M. A. Zlenko, Additive technologies and goods made of metal (FGUP "NAMI", Moscow, 2014)

12. E. Atzeni, A. Salmi, Int. J. Adv. Manuf. Technol. 62(9-12) (2012) 
13. TCT Magazine [online], Available at: http://www.tctmagazine.com/additivemanufacturing/eos-and-airbus-group-innovations-join-forces-on-study-for-3d/ (2018)

14. GE [online], Available at: http://www.ge.com/stories/advanced-manufacturing (2018)

15. SpaceX [online], Available at: http://www.spacex.com/press/2014/05/27/spacexcompletes-qualification-testing-superdraco-thruster (2014)

16. NASA [online], Available at: http://www.nasa.gov/exploration/systems/sls/selective melting.html (2018)

17. DMG-MORI [online], Available at: http://en.dmgmori.com/ (2018) 